\title{
Tipepidine in adolescent patients with depression: a 4 week, open-label, preliminary study
}

This article was published in the following Dove Press journal:

Neuropsychiatric Disease and Treatment

5 May 2014

Number of times this article has been viewed

\author{
Tsuyoshi Sasaki ${ }^{1,2}$ \\ Kenji Hashimoto ${ }^{3}$ \\ Masumi Tachibana' \\ Tsutomu Kurata' \\ Hiroshi Kimura ${ }^{2}$ \\ Hideki Komatsu ${ }^{2}$ \\ Masatomo Ishikawa ${ }^{2}$ \\ Tadashi Hasegawa ${ }^{2}$ \\ Akihiro Shiina' \\ Tasuku Hashimoto ${ }^{2}$ \\ Nobuhisa Kanahara ${ }^{4}$ \\ Tetsuya Shiraishi \\ Masaomi lyol-4 \\ 'Department of Child Psychiatry, \\ Chiba University Hospital, \\ ${ }^{2}$ Department of Psychiatry, Chiba \\ University Graduate School of \\ Medicine, ${ }^{3}$ Division of Clinical \\ Neuroscience, Chiba University \\ Center for Forensic Mental Health, \\ ${ }^{4}$ Division of Medical Treatment and \\ Rehabilitation, Chiba University \\ Center for Forensic Mental Health, \\ Inohana, Chiba, Japan
}

Correspondence: Tsuyoshi Sasaki Department of Child Psychiatry, Chiba University Hospital, Inohana I-8-I, Chiba, 260-8670, Japan

Tel +8I 432262297

Fax +8I 432262297

Email sasaki@faculty.chiba-u.jp

\section{Dear editor}

Depression in children and adolescents is a common, recurrent, and debilitating condition associated with increased psychosocial, and medical morbidity and mortality. ${ }^{1}$

The global prevalence of depression in children and adolescents is $1 \%-2 \%$ and $3 \%-8 \%$, respectively. ${ }^{2}$ Depressive symptoms are also associated with significant functional impairment in school and the work place (often requiring legal interventions), ${ }^{1-5}$ and an increased risk for substance abuse and suicide ${ }^{6-9}$ Clinical guidelines suggest the use of two selective serotonin reuptake inhibitors (SSRI), namely fluoxetine and escitalopram, both of which are effective with generally acceptable safety profiles in the treatment of adolescent depression. ${ }^{10}$ Additionally, combination treatment with an SSRI and psychotherapy, typically cognitive behavioral therapy (CBT), has shown benefit in this cohort. ${ }^{10}$ However, caution is warranted since antidepressants therapy in children and adolescents is associated with increased rates of suicidal ideation ${ }^{11-13}$ and adverse effects, characterized by excessive emotional arousal or behavioral activation. ${ }^{14}$ These results highlight the need for new therapies in adolescent patients with depression, particularly therapies with fewer side effects.

Tipepidine (3-[di-2-thienylmethylene]-1-methylpiperidine) has been used as a non-narcotic antitussive in Japan since 1959. The safety of short-term tipepidine use in children and adults has already been established. Furthermore, no suicide related side effects have been documented for tipepidine. It appears to act by inhibiting G-proteincoupled inwardly rectifying potassium (GIRK) channel currents. ${ }^{15}$ The activation of the GIRK channels causes membrane hyperpolarization through potassium efflux. This inhibition is thought to modulate monoamine levels in the brain, since GIRK channels are coupled with G-protein-coupled receptors, such as 5-hydroxytryptamine (5-HT) ${ }_{1 \mathrm{~A}}$, adrenaline $\alpha_{2}$ and dopamine $\mathrm{D}_{2}$ receptors. ${ }^{15}$ Using in vivo microdialysis, Kawaura et al demonstrated that tipepidine increases levels of 5-HT and catecholamines, including dopamine, in the prefrontal cortex of rats. ${ }^{16}$ Furthermore, Kawaura et $a{ }^{17}$ showed that tipepidine produces antidepressant-like effects in rats subjected to the forced swimming test (a model of depression), by modulating these monoamine systems. Furthermore, our recent preliminary study suggests that tipepidine therapy may prove to be an effective alternative treatment for pediatric patients with ADHD. ${ }^{18}$ Considering these results, we hypothesize that tipepidine can improve adolescent depressive symptoms by modulating monoaminergic neurotransmission, through the inhibition of GIRK channel coupling to monoamine receptors in the brain. 
We report six cases where tipepidine treatment $(30 \mathrm{mg} /$ day) proved effective in treating the symptoms of adolescent depression. The ethics committee of Chiba University Graduate School of Medicine approved the study protocol (G24062), which was performed in accordance with the Declaration of Helsinki II. All subjects and their parents provided written informed consent for study participation, after receiving a full explanation of the study, as well as any potential risks and benefits. This trial was registered on the official database of clinical research (Clinical Trials.gov), on April 17, 2013. ${ }^{19}$ Statistical analyses were performed using the software package SPSS Version 21.0, for Macintosh (SPSS Statistics Desktop; IBM Corporation, Armonk, NY, US).

We recruited a total of ten outpatients from Chiba University Hospital, who were diagnosed according to the ICD-10 criteria for depressive episodes. ${ }^{20}$ However, four subjects dropped out of the trial, because of feelings of mild irritation $(n=2)$ and mild skin eruptions $(n=2)$ less than 2 weeks into the study. These symptoms disappeared several days after the discontinuation of tipepidine. Overall, six subjects received tipepidine hibenzate tablets (Asverin; Mitsubishi Tanabe Pharma Corporation, Osaka, Japan), taken orally at $30 \mathrm{mg}$ /day ( $10 \mathrm{mg}$ after breakfast, $10 \mathrm{mg}$ after lunch, and $10 \mathrm{mg}$ after supper), for 4 weeks. Six adolescent subjects with depression (66\% female, mean age 15.7 years, standard deviation $(\mathrm{SD}) \pm 2.2$ years; mild depressive episode subtype, $n=1$; moderate depressive episode subtype, $n=1$; severe depressive episode subtype, $n=4$ ) were studied. The six subjects were Japanese adolescents. The mean height $(\mathrm{cm})$, weight $(\mathrm{kg})$, and tipepidine hibenzate dosage $(\mathrm{mg} / \mathrm{kg} /$ day) of the six subjects were $158.2 \mathrm{~cm} \pm 9.3 ; 57.3 \mathrm{~kg} \pm 4.9$; and $0.527 \mathrm{mg} / \mathrm{kg} /$ day $\pm 0.044 \mathrm{mg}$, respectively. Four subjects were receiving drug treatment before entry into this trial, namely, quetiapine ( $25 \mathrm{mg} /$ day, $500 \mathrm{mg} /$ day, $\mathrm{n}=2)$, milnacipran (100 $\mathrm{mg} /$ day, $\mathrm{n}=1$ ), and a combination of lamotrigine and blonanserin (400 mg/day and $4 \mathrm{mg} /$ day, respectively, $\mathrm{n}=1$ ), while two subjects were drug-naïve. These treatment regimes were stable for at least 4 weeks prior to enrollment and remained stable through the duration of the trial.

The Mini International Neuropsychiatric Interview for Children and Adolescents (MINI-KID) ${ }^{21}$ was conducted to document any current or past, personal or familial history of mental illness. One subject had a family history of depression in their mother, one subject had a family history of bipolar disorder in their mother, while four subjects had no family history of psychiatric disease. The six subjects completed the Children's Depression Rating Scale-Revised (CDRS-R). ${ }^{22}$ As a result, no significant changes were revealed in general state, weight, height, blood pressure, or heart rate, during the 4 week follow-up period in the six subjects who completed the trial. In the six subjects who completed the trial, a comparison of baseline and the 4 week endpoint showed that CDRS-R total scores (baseline score, 58.83 \pm 10.83 ; 4 week endpoint score, $38.87 \pm 3.33 ; P=0.003, d f=5, t=5.384$ ) and subscores for Difficulty Having Fun (baseline score; $4.33 \pm 0.82$, 4 week endpoint score; $2.67 \pm 0.52 ; P=0.011, d f=5$, $t=3.953$ ), Social Withdrawal (baseline score; 4.00 $\pm 0.89,4$ week endpoint score; $2.83 \pm 0.75 ; P=0.013, d f=5, t=3.796$ ), Appetite Disturbance (baseline score; $3.00 \pm 0.63$, 4 week endpoint score; $2.00 \pm 0.89 ; P=0.012, d f=5, t=3.873$ ), Physical Complaints (baseline score; 3.67 \pm 0.82 , 4 week endpoint score; $1.50 \pm 0.84 ; P=0.006, d f=5, t=4.540$ ), Excessive Guilt (baseline score; $3.17 \pm 0.75$, 4 week endpoint score; $1.83 \pm 0.75$; $P=0.010, d f=5, t=4.000$ ), Low Self-Esteem (baseline score; $4.00 \pm 0.89$, 4 week endpoint score; $2.33 \pm 1.03 ; P=0.011, d f=5$, $t=3.953$ ), Depressed Feelings (baseline score; 4.17 \pm 1.47 , 4 week endpoint score; $2.33 \pm 1.21 ; P=0.038, d f=5, t=2.803$ ), Excessive Weeping (baseline score; $3.83 \pm 2.40$, 4 week endpoint score; $1.67 \pm 0.82 ; P=0.027, d f=5, t=3.081$ ); and Depressed Facial Affect (baseline score; 3.83 \pm 1.17 , 4 week endpoint score; $2.17 \pm 0.75 ; P=0.004, d f=5, t=2.524$ ), improved significantly using paired $t$-test. Wilcoxon signed rank test also detected statistical significance in the CDRS-R total score $(P=0.027)$, as well as subscores for Difficulty Having Fun $(P=0.039)$, Social Withdrawal $(P=0.038)$, Appetite Disturbance $(P=0.034)$, Physical Complaints $(P=0.038)$, Excessive Guilt $(P=0.020)$, Low Self-Esteem $(P=0.039)$, and Depressed Facial Affect $(P=0.026)$. However, a comparison between baseline and the 4 week end-point found subscores for Impaired Schoolwork, Sleep Disturbance, Excessive Fatigue, Irritability, Morbid Ideation, Suicidal Ideation, Listless Speech, and Hypoactivity showed no significant changes. The Wilcoxon signed rank test also failed to detect any statistical significance in subscore changes for Impaired Schoolwork, Sleep Disturbance, Excessive Fatigue, Irritability, Depressed Feelings, Morbid Ideation, Suicidal Ideation, Excessive Weeping, Listless Speech, or Hypoactivity. Tipepidine was well tolerated in the six subjects who completed the trial, with no further dropouts due to side effects. Furthermore, three patients with adolescent depression have been continuing the oral use of tipepidine (30 mg/day) for its efficacy against depressive symptoms for 3 months or more after this trial.

Tipepidine improved symptoms of adolescent depression in the six subjects who completed the trial, as shown by CDRS-R scores. To our knowledge, this is the first report 
demonstrating a beneficial effect for tipepidine in adolescent depression. Tipepidine inhibits GIRK channels and is predicted to modulate brain monoamine levels, in a similar manner to SSRIs, serotonin and norepinephrine reuptake inhibitors (SNRIs) and other antidepressants. Four subjects with depression dropped out during the trial due to feelings of mild irritation and mild skin eruptions. One possible reason for having dropout patients is diagnostic error. There is a chance that some of these children with depression may have been suffering from the onset of bipolar disorder or schizophrenia. Therefore, a follow-up check may be required for the dropout patients to examine their progression.

Recent mapping the of c-Fos-like immunoreactivity (FLI) induction in rat brains identified FLI-positive neurons in several brain areas after acute dosing with different classes of antidepressants. ${ }^{23}$ Very recently Kawahara et $\mathrm{al}^{24}$ showed that a single injection of tipepidine $(20 \mathrm{mg} / \mathrm{kg}$ or $40 \mathrm{mg} / \mathrm{kg}$ ) in rats, increased FLI-positive neurons in the central nucleus of the amygdala $(\mathrm{CeA})$ in a manner similar to the tested antidepressants, as well as inducing the characteristic increase in FLI-positive neurons in six other brain regions, including the nucleus accumbens (NAcc). This latter effect was not observed with other antidepressants. Therefore, further detailed studies investigating tipepidine induced dopamine activation in the $\mathrm{CeA}, \mathrm{NAc}$, and its neural pathways are warranted.

The main limitation of our study is its small sample size ( $n=6$ evaluable subjects). Another is the low proportion of drug naïve subjects. Additional trials are needed to evaluate the efficacy and safety for tipepidine use in adolescent depression. Although tipepidine is widely used, however, there are reports ${ }^{25-27}$ indicating a possible toxic effect like agitation, fixed drug eruption and toxic epidermal necrolysis also in pediatric populations. So we must pay attention to the mood symptoms, especially irritability and cutis symptoms, because there were patients for whom a feeling of irritation and a cutis symptom appeared in this tipepidine study. Also, future studies with greater analytical power, using larger sample sizes and more drug naïve subjects will be necessary to determine tipepidines efficacy and safety.

In conclusion, our pilot study suggests that tipepidine therapy may prove to be an effective alternative treatment for adolescent patients with depression. However, the longterm safety of tipepidine still needs to be assessed, as a cough suppressant therapy is usually completed within 1 week. In addition, the side effects detected here need careful evaluation, as part of more detailed randomized, double-blind studies into this encouraging finding for tipepidine in adolescent depression.

\section{Disclosure}

The authors report no conflicts of interest in this work.

\section{References}

1. Brent DA, Maalouf FT. Pediatric depression: is there evidence to improve evidence-based treatments? J Child Psychol Psychiatry. 2009;50:143-152.

2. Fleming JE, Offord DR. Epidemiology of childhood depressive disorders: a critical review. J Am Acad Child Adolesc Psychiatry. 1990;29(4):571-580.

3. Kandel DB, Davies M. Adult sequelae of adolescent depressive symptoms. Arch Gen Psychiatry. 1986;43(3):255-262.

4. Kovacs M, Feinberg TL, Crouse-Novak MA, Paulauskas SL, Finkelstein R. Depressive disorders in childhood. I. A longitudinal prospective study of characteristics and recovery. Arch Gen Psychiatry. 1984;41(3): 229-237.

5. Pfeffer CR, Klerman GL, Hurt SW, et al. Suicidal children grow up: demographic and clinical risk factors for adolescent suicide attempts. J Am Acad Child Adolesc Psychiatry. 1991;30(4):609-616.

6. Birmaher B, Ryan ND, Williamson DE, Brent DA, Kaufman J. Childhood and adolescent depression: a review of the past 10 years. Part II. J Am Acad Child Adolesc Psychiatry. 1996;35(12):1575-1583.

7. Birmaher B, Brent D, AACAP Work Group on Quality Issues, et al. Practice parameter for the assessment and treatment of children and adolescents with depressive disorders. J Am Acad Child Adolesc Psychiatry. 2007;46(11):1503-1526.

8. Brent DA. Correlates of the medical lethality of suicide attempts in children and adolescents. J Am Acad Child Adolesc Psychiatry. 1987;26(1):87-91.

9. Maalouf FT, Brent DA. Pharmacotherapy and psychotherapy of pediatric depression. Expert Opin Pharmacother. 2010;11:2129-2140.

10. Adegbite-Adeniyi C, Gron B, Rowles BM, Demeter CA, Findling RL. An update on antidepressant use and suicidality in pediatric depression. Expert Opin Pharmacother. Oct 2012;13(15):2119-2130.

11. Bridge JA, Iyengar S, Salary CB, et al. Clinical response and risk for reported suicidal ideation and suicide attempts in pediatric antidepressant treatment: a meta-analysis of randomized controlled trials. JAMA. 2007;297:1683-1696.

12. Olfson M, Marcus SC, Shaffer D. Antidepressant drug therapy and suicide in severely depressed children and adults: a case-control study. Arch Gen Psychiatry. 2006;63:865-872.

13. Gibbons RD, Hur K, Bhaumik DK, Mann JJ. The relationship between antidepressant prescription rates and rate of early adolescent suicide. Am J Psychiatry. 2006;163:1898-1904.

14. Leckman JF. The risks and benefits of antidepressants to treat pediatriconset depression and anxiety disorders: a developmental perspective. Psychother Psychosom. 2013;82(3):129-131.

15. Takahama K, Shirasaki T, Soeda F. Central mechanisms III: neuronal mechanisms of action of centrally acting antitussives using electrophysiological and neurochemical study approaches. Handb Exp Pharmacol. 2009:219-240.

16. Kawaura K, Honda S, Soeda F, Shirasaki T, Takahama K. [A novel antidepressant-like action of drugs possessing GIRK channel blocking action in rats]. Yakuqaku Zasshi. 2010;130(5):699-705. Japanese.

17. Kawaura K, Miki R, Urashima Y, Kawahara R, et al. Pharmacological mechanisms of antidepressant-like effect of tipepidine in the forced swimming test. Behav Brain Res. 2012;226(2):381-385.

18. Sasaki T, Hashimoto K, Tachibana M, et al. Tipepidine in children with attention deficit/hyperactivity disorder: a 4-week, openlabel, preliminary study. Neuropsychiatr Dis Treat. 2014;10: 147-151.

19. Chiba University. An open study of tipepidine hibenzate in adolescent patients with depression). Available from: http://clinicaltrials.gov/ ct2/show/NCT01835847. NLM identifier: NCT01835847. Accessed March 31, 2014. 
20. World Health Organization. The ICD-10 Classification of Mental and Behavioural Disorders: Clinical Descriptions and Diagnostic Guidelines First Japanese edition: Igaku-shoin Ltd, Tokyo, Japan, 1993.

21. Sheehan DV, Sheehan KH, Shytle RD, et al. Reliability and validity of the Mini International Neuropsychiatric Interview for Children and Adolescents (MINI-KID). J Clin Psychiatry. 2010;71(3):313-326.

22. Poznanski EO, Grossman JA, Buchsbaum Y, et al. Preliminary studies of the reliability and validity of the children's depression rating scale. J Am Acad Child Psychiatry. 1984;23:191-197.

23. Beck $\mathrm{CH}$. Acute treatment with antidepressant drugs selectively increases the expression of c-fos in the rat brain. J Psychiatry Neurosci. $1995 ; 20(1): 25-32$.
24. Kawahara R, Soeda F, Kawaura K, et al. Effect of tipepidine with novel antidepressant-like action on c-fos-like protein expression in rat brain. Brain Res. 2013;1513:135-142.

25. Imai Y, Ishii W, Endo A, et al. Tipepidine hibenzate intoxication. Pediatr Int. 2011;53(5):779-781.

26. Murao S, Watanabe H. Acute Confusional State Caused by Tipepidine Hibenzate Intoxication in an Elderly: Caution About Suspended Solution. J Med Cases. 2013;4(12):773-774.

27. Iwabuchi $\mathrm{C}$, Kanto H, Ohashi N, Itoh M. Fixed drug eruption induced by tipepidine hibenzate. J Dermatol. 2010;37(5):502-503.

\section{Publish your work in this journal}

Neuropsychiatric Disease and Treatment is an international, peerreviewed journal of clinical therapeutics and pharmacology focusing on concise rapid reporting of clinical or pre-clinical studies on a range of neuropsychiatric and neurological disorders. This journal is indexed on PubMed Central, the 'PsycINFO' database and CAS.
The manuscript management system is completely online and includes a very quick and fair peer-review system, which is all easy to use. Visit http://www.dovepress.com/testimonials.php to read real quotes from published authors.

Submit your manuscript here: http://www.dovepress.com/neuropsychiatric-disease-and-treatment-journal 